\title{
Comparison of the afIR gene sequences of strains in Aspergillus section Flavi
}

\begin{abstract}
Correspondence
Gwo-Fang Yuan

gfy@firdi.org.tw
\end{abstract}

Received 31 May 2005

Accepted 22 August 2005
Chao-Zong Lee, Guey-Yuh Liou and Gwo-Fang Yuan

Bioresource Collection and Research Center, Food Industry Research and Development Institute, PO Box 246, Hsinchu 300, Taiwan, ROC

\begin{abstract}
Aflatoxins are polyketide-derived secondary metabolites produced by Aspergillus parasiticus, Aspergillus flavus, Aspergillus nomius and a few other species. The toxic effects of aflatoxins have adverse consequences for human health and agricultural economics. The afIR gene, a regulatory gene for aflatoxin biosynthesis, encodes a protein containing a zinc-finger DNA-binding motif. Although Aspergillus oryzae and Aspergillus sojae, which are used in fermented foods and in ingredient manufacture, have no record of producing aflatoxin, they have been shown to possess an afIR gene. This study examined 34 strains of Aspergillus section Flavi. The afIR gene of 23 of these strains was successfully amplified and sequenced. No afIR PCR products were found in five $A$. sojae strains or six strains of $A$. oryzae. These PCR results suggested that the afIR gene is absent or significantly different in some $A$. sojae and $A$. oryzae strains. The sequenced afIR genes from the 23 positive strains had greater than $96.6 \%$ similarity, which was particularly conserved in the zinc-finger DNA-binding domain. The afIR gene of $A$. sojae has two obvious characteristics: an extra CTCATG sequence fragment and a $\mathrm{C}$ to $\mathrm{T}$ transition that causes premature termination of AFLR protein synthesis. Differences between A. parasiticus/A. sojae and A. flavus/ $A$. oryzae aflR genes were also identified. Some strains of $A$. flavus as well as $A$. flavus var. viridis, $A$. oryzae var. viridis and $A$. oryzae var. effuses have an $A$. oryzae-type aflR gene. For all strains with the $A$. oryzae-type afIR gene, there was no evidence of aflatoxin production. It is suggested that for safety reasons, the afIR gene could be examined to assess possible aflatoxin production by Aspergillus section Flavi strains.
\end{abstract}

\section{INTRODUCTION}

Aflatoxins are potent carcinogenic compounds that occur naturally as secondary metabolites produced by some strains of Aspergillus flavus, Aspergillus parasiticus, Aspergillus nomius and Aspergillus tamarii. These aflatoxin-producing species, and the non-aflatoxigenic species Aspergillus oryzae and Aspergillus sojae, which are widely used in industry, especially for oriental food fermentation, belong to Aspergillus section Flavi. In particular, A. flavus and A. parasiticus have numerous phenotypic similarities to A. oryzae and A. sojae, respectively (Kurtzman et al., 1986; Klich \& Pitt, 1988). The primary procedure employed to identify isolates of Aspergillus section Flavi depends on their morphologies (Murakami et al., 1982); various molecular-based methods (Yuan et al., 1995; Kumeda \& Asao, 1996; Geiser et al., 1998; Lee et al., 2004) have also been used to differentiate closely related

Abbreviations: BCRC, Bioresource Collection and Research Center; ITS, internal transcribed spacer.

The GenBank/EMBL/DDBJ accession numbers for the Aspergillus section Flavi afIR gene sequences reported in this paper are AY650922-AY650944.
Aspergillus section Flavi strains. However, it is still difficult to identify these species.

Aflatoxin contamination of agricultural commodities, such as maize, peanuts and cottonseed, is a serious risk to human and animal health, and has a significant economic impact. Over 30 years of investigations into the aflatoxin biosynthetic pathway has identified more than 20 enzymes involved. Most of the aflatoxin-related genes are clustered within a $75 \mathrm{~kb}$ region of the genome (Trail et al., 1995; Yu et al., 1995; Woloshuk \& Prieto, 1998). The aflR gene, which regulates these clustered genes, has been identified in $A$. flavus, A. parasiticus, A. sojae and A. oryzae. The predicted AFLR protein contains a GAL4-type zinc-finger motif that transcriptionally activates most of the structural pathway genes, such as ver-1 and nor-1 (Woloshuk et al., 1994; Trail et al., 1995; Ehrlich et al., 1999a). Notably, although there is no evidence of aflatoxin production by the non-aflatoxinproducing fungi $A$. oryzae and A. sojae, some genes (nor-1, ver-1, omt- $A$ and aflR) needed for aflatoxin biosynthesis are present, but not expressed, in these fungi (Woloshuk et al., 1994; Klich et al., 1995, 1997; Kusumoto et al., 1998a; Watson et al., 1999). The sequence variability of a region of the aflR gene has been studied in a few strains of $A$. flavus, $A$. 
parasiticus, A. oryzae and A. sojae; however, these studies have not achieved a high degree of differentiation for Aspergillus section Flavi strains (Chang et al., 1995a).

The goal of this investigation was to elucidate whether a common but specific sequence variability occurs within the entire aflR gene of the non-aflatoxin-producing species $A$. oryzae and A. sojae of Aspergillus section Flavi. This study performs a sequence comparison of the entire aflR gene for strains of Aspergillus section Flavi and examines the potential significance of the differences in the aflR sequences and the encoded AFLR protein. It was found that a particular sequence variability differentiates some species in Aspergillus section Flavi and can be used to identify nonfunctionality of the AFLR protein.

\section{METHODS}

Fungal strains and culture conditions. The fungal strains employed in this investigation (Table 1) were collected at the Bioresource Collection and Research Center (BCRC) at the Food Industry Research and Development Institute (FIRDI), Taiwan. The mycelial mats were prepared for DNA extraction by harvesting spore suspensions from approximately 7-day-old slants and inoculating these suspensions into $50 \mathrm{ml}$ potato dextrose broth (PDB) in $250 \mathrm{ml}$ flasks, which were incubated at $25^{\circ} \mathrm{C}$ for $48-72 \mathrm{~h}$. Mycelial masses were collected by suction filtration, ground to fine powder in liquid nitrogen and stored at $-80^{\circ} \mathrm{C}$.

Preparation of fungal genomic DNA. Each $20 \mathrm{mg}$ of mycelial powder in a $1.5 \mathrm{ml}$ centrifuge tube was resuspended in $600 \mu \mathrm{l}$ extraction buffer (100 mM Tris/ $\mathrm{HCl}, \mathrm{pH} 8 \cdot 0,100 \mathrm{mM} \mathrm{NaCl}, 20 \mathrm{mM}$ EDTA, $2 \%$ SDS) and incubated at $60{ }^{\circ} \mathrm{C}$ for $15 \mathrm{~min}$. Mycelial lysates were extracted from mycelial masses and combined with an equal volume of phenol/chloroform (1:1). After mixing and centrifugation for $5 \mathrm{~min}$ at $12500 \mathrm{~g}$, the aqueous phase was collected. After a chloroform/isoamyl alcohol $(24: 1)$ extraction, the sample was centrifuged as previously described. Nucleic acids were precipitated using $0 \cdot 7$ vol. 2-propanol and redissolved in sterilized distilled water after drying. The RNA was removed by incubation with DNase-free RNase at $37^{\circ} \mathrm{C}$ for $1 \mathrm{~h}$. Agarose gel electrophoresis $(0.7 \%$ agarose in $1 \times$ Tris/borate/EDTA) was used to evaluate DNA integrity. The DNA concentration was measured with a spectrophotometer (model U-2001, Hitachi).

PCR amplification of afIR gene fragments. To sequence each aflR gene, roughly $1700 \mathrm{bp}$ with the ORF, $200 \mathrm{bp}$ upstream and $160 \mathrm{bp}$ downstream was amplified from genomic DNA using four primer pairs: F1/R1, F2/R2, F3/R3 and F4/R4 (MD Bio Inc., Taipei, Taiwan or DNAFax Inc., Taipei, Taiwan) (Table 2, Fig. 1). The primer sequences correspond to those of $A$. parasiticus aflR cDNA (GenBank accession no. L26222). The PCR reactions $(50 \mu \mathrm{l})$ contained $0.2 \mathrm{mg}$ genomic DNA as template, deoxynucleoside triphosphates at $0.2 \mathrm{mM}$ each, primers at $100 \mathrm{pmol}$ each, $1 \cdot 1 \mathrm{U}$ DNA polymerase and $1 \times$ reaction buffer. The $\mathrm{PCR}$ reactions were performed with a model 9600 DNA thermal cycler (Applied Biosystems) programmed as follows: initial denaturation at $94{ }^{\circ} \mathrm{C}$ for $2 \mathrm{~min}$ followed by 30 cycles at $94{ }^{\circ} \mathrm{C}$ for $10 \mathrm{~s}, 60^{\circ} \mathrm{C}$ for $30 \mathrm{~s}$ and $72{ }^{\circ} \mathrm{C}$ for $2 \mathrm{~min}$. A final extension at $72{ }^{\circ} \mathrm{C}$ for 5 min was performed at the end of amplification. Alternatively, primer pairs F5/R5 and F6/R6 (Table 2) were employed to amplify the aflR gene at the lower annealing temperature of $55^{\circ} \mathrm{C}$. The internal transcribed spacer (ITS) fragment of the rRNA gene was amplified using primers ITS3 and ITS4 (White et al., 1990) as a control for the PCR reaction.
Each PCR product was analysed by electrophoresis on a $1.5 \%$ agarose gel in $1 \times$ Tris/borate/EDTA to measure the amplified fragment size.

DNA sequencing and analysis. The PCR products were purified with a High Pure PCR Product Purification kit (Boehringer Mannheim). Sequence reactions were conducted with an ABI PRISM Dye Terminator Cycle Sequencing Ready Reaction kit and analysed by electrophoresis on an ABI 373A DNA sequencer (Applied Biosystems). Sequence ambiguities were identified by comparison with their opposite strand sequences. Sequences of the four fragments (F1-R1, F2-R2, F3-R3 and F4-R4) were assembled to yield the entire aflR gene sequence; the aflR sequences of each strain were aligned using CLUSTAL X 1.83 (Thompson et al., 1997). The alignment of all sequences was visually assessed and optimized when necessary. Phylogenetic evaluation was accomplished by applying a neighbour-joining program from the PHYLIP 3.63 package (Felsenstein, 2004). Phylogenetic trees were rooted with Aspergillus pseudotamarii (Ehrlich et al., 2003). Finally, a bootstrap analysis with 1000 replications was performed. Trees were viewed using TreeView (Page, 1996).

\section{RESULTS AND DISCUSSION}

Although A. oryzae and A. sojae, used traditionally in the production of fermented foods such as rice wine and soy sauce, have no record of producing aflatoxin, aflatoxinsynthesis genes are nevertheless present in many strains of these moulds (Woloshuk et al., 1994; Chang et al., 1995a; Klich et al., 1995, 1997; Kusumoto et al., 1998a; Watson et al., 1999). Therefore, there is concern regarding the potential expression of aflatoxin genes from $A$. oryzae and $A$. sojae under certain conditions, since such expression could cause severe health problems. The food industry requires strong evidence to prove the safety of the A. oryzae and A. sojae strains used in food production. The aflR gene is the principal regulator of the aflatoxin production pathway (Chang et al., 1993; Payne et al., 1993; Woloshuk et al., 1994). Previous research has demonstrated that the AFLR protein can bind the promoter region of each aflatoxin synthesis gene and activate gene expression (Woloshuk et al., 1994; Trail et al., 1995; Ehrlich et al., 1999b). In addition, the aflR gene has an autoregulation function (Chang et al., 1995b). Absence of the aflR gene or the presence of an abnormal aflR gene would be a strong indicator that a strain cannot produce aflatoxin. In this study, 34 strains of Aspergillus section Flavi were selected based upon diversity of source and origin, and aflatoxigenic capability (Wei \& Jong, 1986); the type strain for each species was also included. The identification of each strain was confirmed by morphological observations.

\section{Some strains of $A$. oryzae and $A$. sojae have no afIR gene}

The aflR gene was amplified successfully for 23 out of the 34 strains of Aspergillus section Flavi (Table 1) tested. The obtained sequences were deposited at NCBI under accession nos AY650922-AY650944. However, five strains of A. sojae (BCRC 30419, 30431, 31200, 32265 and 38021) and six strains of A. oryzae (BCRC 32268, 32269, 30237, 31646, 31659 and 31658) did not generate any PCR products for 
Table 1. Strains of Aspergillus section Flavi tested in this study

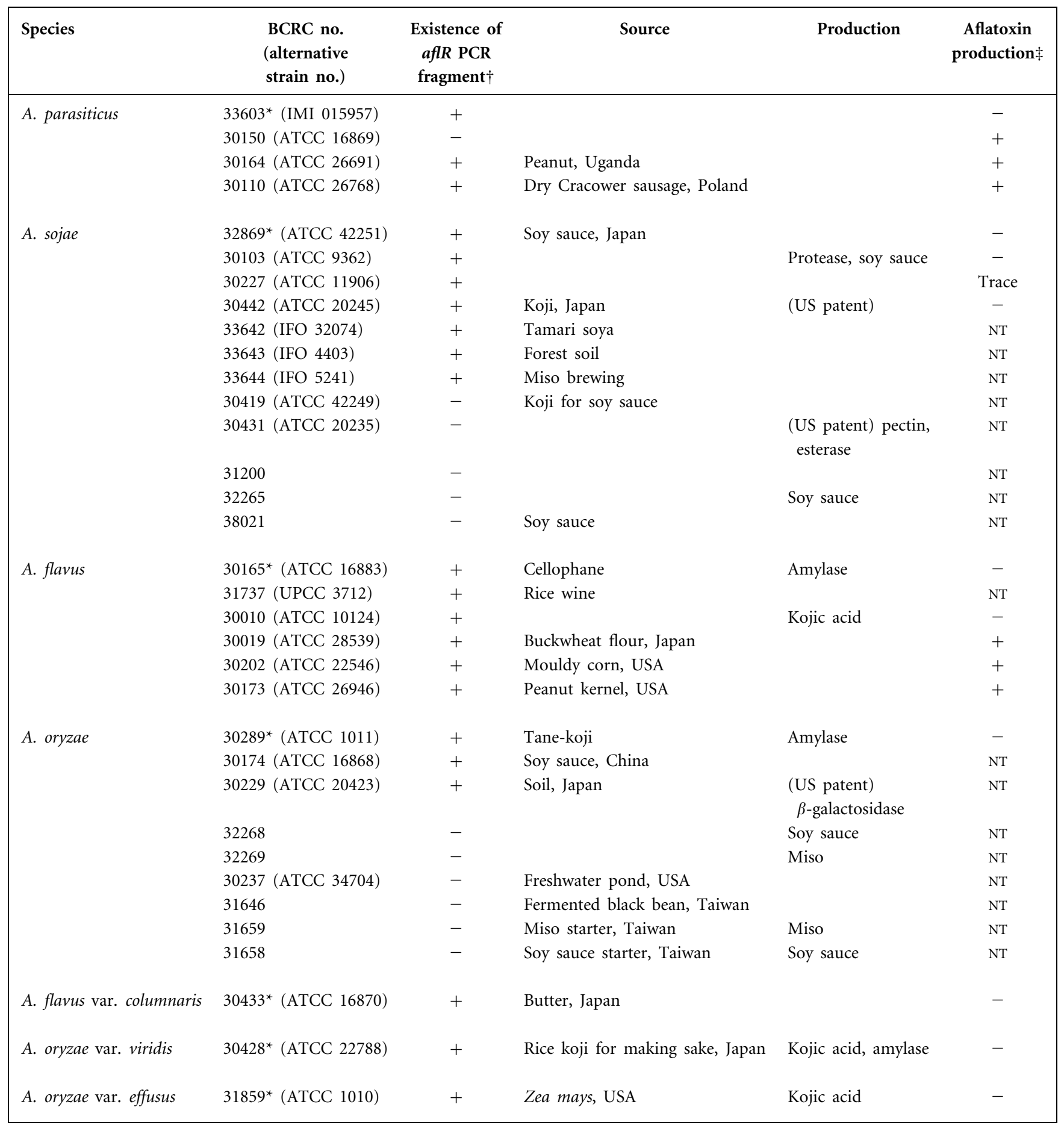

*Type strain.

$\dagger+$, Positive; - , negative.

$\ddagger+$, Aflatoxin producer; -, non-aflatoxin producer; NT, not tested (Wei \& Jong, 1986).

the aflR gene (Table 1). Although PCR conditions were improved by using other highly conserved primer pairs (F5/R5, F6/R6) and a low annealing temperature $\left(55^{\circ} \mathrm{C}\right)$, the 11 strains originally lacking a PCR product for an aflR gene still did not yield any PCR products typical of the aflR gene. All of the 23 positive strains generated the expected PCR products and all 34 strains tested produced the ITS fragment of the rDNA gene (ITS3-ITS4) as the control. 
Table 2. Primers used to amplify aflR gene fragments

\begin{tabular}{|c|c|c|}
\hline Primer ${ }^{*}$ & Sequence & Position $\dagger$ \\
\hline $\mathrm{F} 1$ & 5'-TCGGTACGTAAACAAGGAAC & -232 to -206 (20-mer) \\
\hline F2 & 5'-CCGATTTCTTGGCTGAGT & 581-598 (18-mer) \\
\hline F3 & 5'-GCTGTCTGACGGAAGAGCG & 1034-1052 (19-mer) \\
\hline $\mathrm{F} 4$ & 5'-GCAATCCGCGCGCTCCCAGT & 197-216 (20-mer) \\
\hline F5 & 5'-GGCCTGTGCTCGGTGTAT & 132-149 (18-mer) \\
\hline F6 & 5'-CAATGGTAGCAGTAGCGTCT & $408-427$ (20-mer) \\
\hline $\mathrm{R} 1$ & 3'-AGTTGAGCCGCTGGTAGTCT & 245-226 (20-mer) \\
\hline $\mathrm{R} 2$ & 3'-CСТАACACACСТАСТССТ & 1110-1083 (18-mer) \\
\hline R3 & 3'-CCTAGGCAGAAACAGTACCA & 1527-1508 (20-mer) \\
\hline R4 & 3'-GCTGGGCAAGGAGCTCAGCC & 667-648 (20-mer) \\
\hline R5 & 3'-GAAAAGAGTGGTCTCAGG & $452-435$ (18-mer) \\
\hline R6 & 3'-TACCGATGAACGACTCGTAC & 1320-1301 (20-mer) \\
\hline
\end{tabular}

${ }^{\star} \mathrm{F}$, forward primer; $\mathrm{R}$, reverse primer.

$\dagger$ The sites corresponding to those of the A. parasiticus aflR cDNA (GenBank accession no. L26222).

Earlier studies did not identify an aflR transcript in A. oryzae or A. sojae (Klich et al., 1997; Kusumoto et al., 1998b; Matsushima et al., 2001a). Our inability to amplify aflR implies that the aflR gene is missing or highly abnormal in some strains of these two species. Kusumoto et al. (1998b) also noted that $A$. oryzae IFO 30104 lacks the aflR gene. Some filamentous fungi traits can be unexpectedly lost, especially in cultures maintained in the laboratory for long periods (Bennett et al., 1997). In this study, some of the test strains were found to lack an aflR gene. A degree of genetic variability was found to exist in other isolates that did contain an aflR gene homologue. Numerous methods have been used to differentiate A. parasiticus from A. sojae, and A. flavus from A. oryzae (Yuan et al., 1995; Kumeda \& Asao, 1996; Lee et al., 2004). The putative absence of aflR in these A. sojae and $A$. oryzae strains offers a practical solution for selecting a completely safe industrial strain that cannot produce aflatoxin.

\section{Level of afIR sequence similarity}

Nucleotide analysis showed greater than $96 \cdot 6 \%$ similarity for the entire aflR gene sequence from 23 strains of Aspergillus. The sequence similarity for the seven strains of A. sojae was nearly $100 \%$. These finding are consistent with the results obtained by Kurtzman et al. (1986), indicating a high degree of DNA similarity among species in Aspergillus section Flavi; their Cot value calculation results identified $100 \%$ relatedness between A. flavus and A. oryzae. A previous study also showed that 16 strains of $A$. flavus or $A$. oryzae could not be clearly differentiated by the sequence in the ITS1-5•8S-ITS2 region of rDNA (Lin et al., 1995).

\section{Variability of promoter and zinc-finger motif of afIR}

Chang et al. (1995a) and Ehrlich et al. (1999b) have studied aflR sequences in the region -130 to -91 , which may be important for aflR function, and have found that they are all the same, except at position -115 , where A. parasiticus/ A. sojae and A. flavus/A. oryzae have $\mathrm{C}$ and $\mathrm{T}$, respectively (Table 3 ). The region +85 to +168 is putatively translated into the CX2CX6CX6CX2CX6C binuclear-type zinc-finger motif (amino acid positions 29-56). The six cysteine residues in the motif were all conserved at the amino acid level in the 23 strains examined; however, some variation occurred in nucleotide residues (Table 3 ). The $T \leftrightarrow C$ transition at position 102, $\mathrm{T}$ in A. parasiticus/A. sojae, $\mathrm{C}$

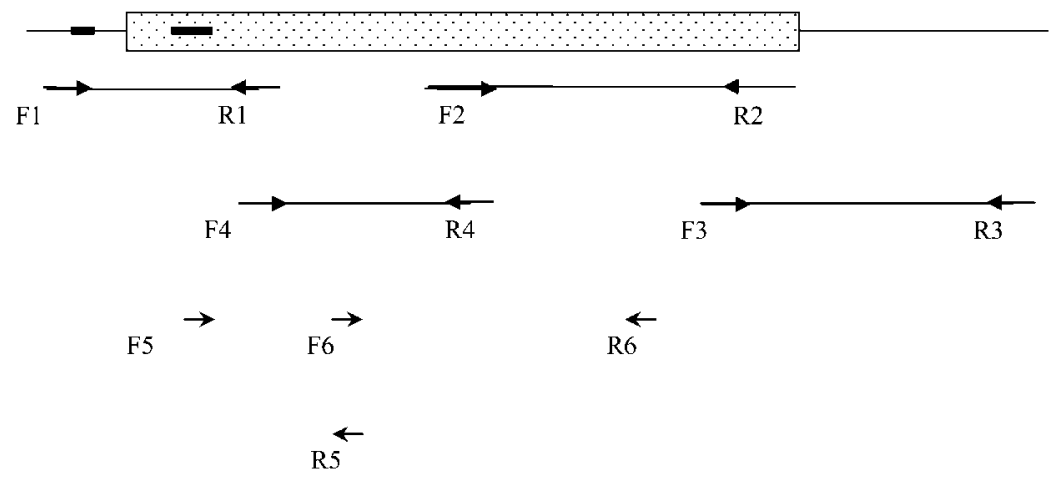

Fig. 1. Positions of primers used to amplify segments of the afIR gene. Dotted bar, afIR ORF; black bar within dotted bar, zinccluster motif; black bar outside dotted bar, AFLR recognition site. 


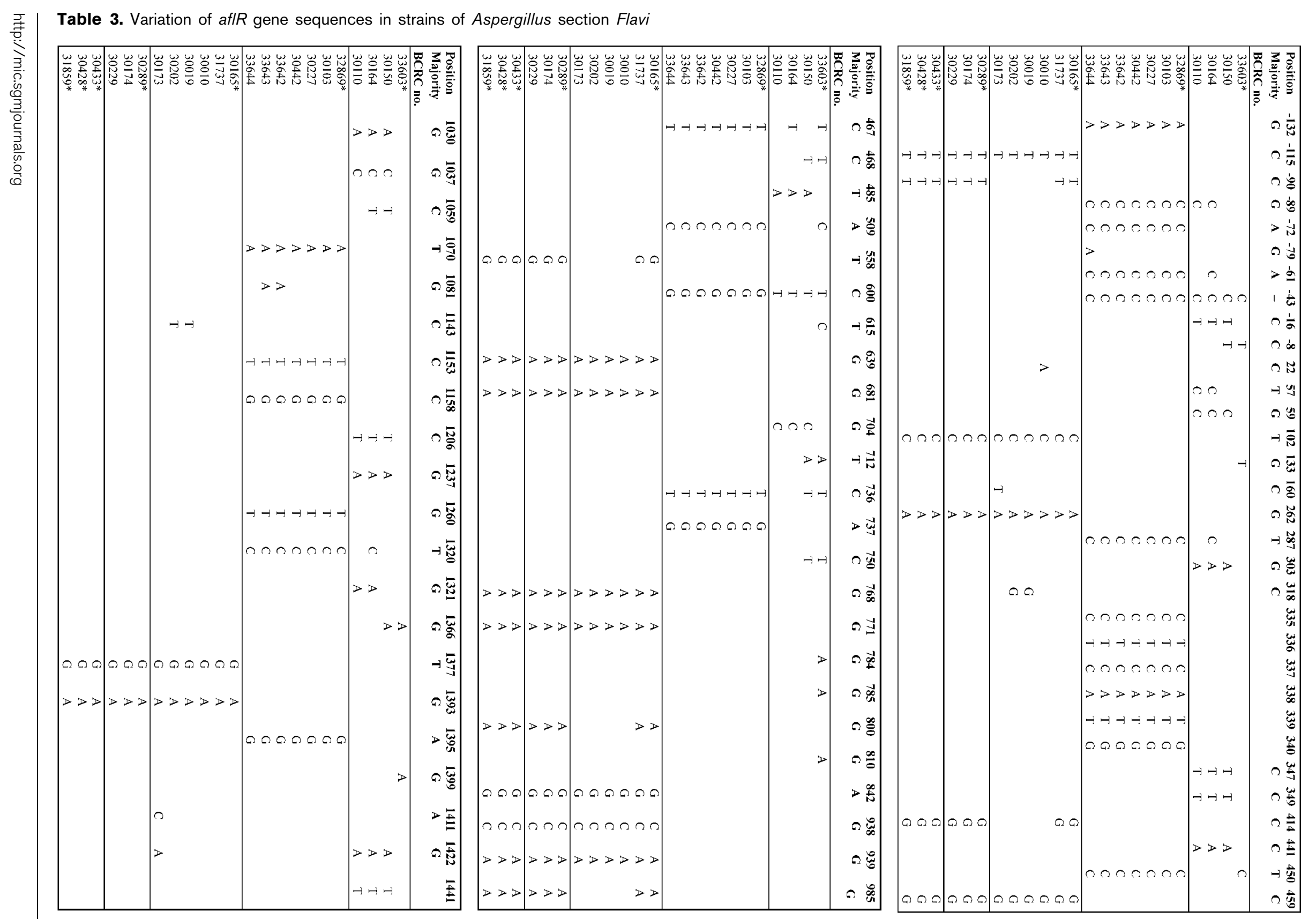


in A. flavus/A. oryzae, did not alter the predicted amino acid residue, Ser, at position 34 . These sequencing results indicated that the promoter and DNA-binding motif regions of the aflR gene are highly conserved. However, individual alterations still occur, e.g. A. parasiticus BCRC 33603 has a $\mathrm{G} \rightarrow \mathrm{T}$ substitution at position 133 , changing the expected amino acid residue from Ala to Ser, and A. flavus BCRC 30173 has a different predicted amino acid residue (Leu $\rightarrow$ Phe), owing to a $\mathrm{C} \rightarrow \mathrm{T}$ substitution at position 160 .

\section{afIR sequences of $A$. sojae are significantly different from those of other strains}

Of the 12 strains of $A$. sojae studied, aflR could be amplified from seven strains. The aflR genes of these $A$. sojae strains are readily distinguished from those of the other species by the six-base insertion (CTCATG) at nucleotides 335-340, and their distinctive nucleotide changes (A, C, G, A, T, G, T, $\mathrm{G})$ at the following positions: $-132,-72,737,1070,1153$, 1158, 1260 and 1395 (Table 3). These differences produced two extra amino acids, Ala and His, at residues 114 and 115, and a stop codon at an arginine codon at position 385, as well as two distinct amino acid substitutions, Cys-246 and His-357 (Table 4). The premature stop codon in the aflR of A. sojae caused truncation by 62 residues of the C-terminal region. These effects have been found by other workers (Matsushima et al., 2001b; Takahashi et al., 2002). Although the HAHA motif is not important, the missing $\mathrm{C}$ terminal of the AFLR protein is essential for aflatoxin production (Matsushima et al., 2001a; Takahashi et al., 2002). It is believed that an acidic amino acid region of GAL4, AFLR and some other proteins constitutes the activation function of these DNA-binding regulators. The activation function of the AFLR protein is eliminated by the C-terminal deletion that results from the stop codon within the aflR gene (Chang et al., 1999). A recently published report confirms that the truncated A. sojae AFLR cannot activate transcription of aflatoxin biosynthetic genes and does not interact with aflJ, a co-activator gene of the aflatoxin biosynthesis pathway (Chang, 2004). No aflatoxin production has been identified for A. sojae, a commonly used industrial organism. In this study, all the aflR genes in the seven A. sojae strains from which they were amplified showed $100 \%$ identity, suggesting the existence of a very small possibility of aflatoxin production, perhaps through the activity of an alternative allele. Some studies have identified a duplicated aflR gene in A. parasiticus; however, the second aflR gene does not completely replace the first aflR gene (Chang \& Yu, 2002; Cary et al., 2002). We suggest that the aflR gene of these $A$. sojae strains cannot function normally and, therefore, cannot produce aflatoxin. It is very likely that these $A$. sojae strains are as safe as strains that lack an aflR gene.

\section{Using afIR to distinguish $A$. parasiticus/A. sojae from $A$. flavus/A. oryzae}

A detailed comparison of the aflR gene sequences demonstrated that certain base variations can be used to differentiate A. parasiticus/A. sojae from A. flavus/A. oryzae. These differences comprise ten transitions (at positions - 115, 102, $262,639,681,768,771,842,939$ and 1393), three transversions (at positions 459, 938 and 1377) and one deletion (at position $-43, \mathrm{C} \rightarrow-$ ). Some of these variations result in amino acid changes (Table 4). Phylogenetic trees were generated based on the aflR gene and the predicted AFLR protein sequences, and these separated A.parasiticus/A. sojae and A. flavus/A. oryzae into two groups (Fig. 2). The topology of the neighbour-joining tree of the aflR gene sequence is the same as that constructed from the amino acid sequence (Fig. 2). A. parasiticus/A. sojae can be differentiated from A.

Table 4. Sequence variation of afIR and the predicted AFLR protein in Aspergillus section Flavi

Nucleotides subject to variation are shown in bold, underlined type.

\begin{tabular}{|lcllll|}
\hline Sequence & Position & \multicolumn{3}{c}{ Species } \\
\cline { 3 - 6 } & & A. parasiticus & A. sojae & A. flavus & A. oryzae \\
\hline DNA & 262 & $\underline{G G G}$ & $\underline{G G G}$ & $\underline{\text { AGG }}$ & $\underline{\text { AGG }}$ \\
Amino acid & 88 & Gly & Gly & Arg & Arg \\
DNA & $335-340$ & GCT & GCTCATGCT & GCT & GCT \\
Amino acid & $114-115$ & A & AHA & A & A \\
DNA & $736-737$ & $\underline{\text { TAC/CAC }}$ & $\underline{\text { TGC }}$ & $\underline{\text { CAC }}$ & $\underline{\text { CAC }}$ \\
Amino acid & 246 & Tyr/His & Cys & His & His \\
DNA & 842 & AAG & AAG & AGG & AGG \\
Amino acid & 281 & Lys & Lys & Arg & Arg \\
DNA & $938-939$ & GGG & GGG & GCA & GCA \\
Amino acid & 313 & Gly & Gly & Ala & Ala \\
DNA & 1070 & CTC & CAC & CTC & CTC \\
Amino acid & 357 & Leu & His & Leu & Leu \\
DNA & 1153 & $\underline{\text { CGA }}$ & $\underline{\text { TGA }}$ & $\underline{\text { CGA }}$ & $\underline{\text { CGA }}$ \\
Amino acid & 385 & Arg & Terminate & Arg & Arg \\
\hline
\end{tabular}






Fig. 2. Neighbour-joining trees of (A) aflR gene sequences and (B) predicted AFLR protein sequences of Aspergillus section Flavi strains. Topologies were rooted with Aspergillus pseudotamarii (AF441427 and AF441428) (Ehrlich et al., 2003). Numbers given on branches indicate the confidence level from a 1000-replicate bootstrap sampling (frequencies below $50 \%$ are not indicated). Aflatoxin production: + , positive; - , negative; NT, not tested.

Table 5. Comparison of the aflR sequence of strains of $A$. flavus with other strains of Aspergillus section Flavi

Nucleotides subject to variation are shown in bold, underlined type. Amino acids subject to variation are shown in bold type.

\begin{tabular}{|c|c|c|c|c|c|c|}
\hline \multirow[t]{2}{*}{ Sequence } & \multirow[t]{2}{*}{ Position } & \multicolumn{5}{|c|}{ Species or strain } \\
\hline & & A. parasiticus & A. sojae & A. flavus & $\begin{array}{c}\text { A. flavus } \\
30165,31737\end{array}$ & A. oryzae \\
\hline DNA & -90 & $\mathrm{C}$ & $\mathrm{C}$ & C & $\mathrm{T}$ & $\mathrm{T}$ \\
\hline DNA & 414 & CCㅡㅡ & CCE & CCE & CCG & CCG \\
\hline Amino acid & 138 & Pro & Pro & Pro & Pro & Pro \\
\hline DNA & 558 & TCT & TCT & TCT & TCG & TCG \\
\hline Amino acid & 186 & Ser & Ser & Ser & Ser & Ser \\
\hline DNA & 800 & TGGC & TGC & TG $\underline{C}$ & TÁC & TAC \\
\hline Amino acid & 267 & Cys & Cys & Cys & Tyr & Tyr \\
\hline DNA & 985 & $\underline{\text { GGT }}$ & $\underline{\text { GGT }}$ & $\underline{\text { GGT }}$ & $\underline{\mathbf{A G T}}$ & $\underline{\mathrm{AGT}}$ \\
\hline Amino acid & 329 & Gly & Gly & Gly & Ser & Ser \\
\hline
\end{tabular}


flavus/A. oryzae by morphological observation by an experienced mycologist. This study presents a simple technique, by amplifying and sequencing the aflR gene, for differentiating A. parasiticus/A. sojae from A. flavus/A. oryzae. This method can be compared with the single-strand conformation polymorphism (SSCP) method studied by Kumeda \& Asao (1996).

\section{A. oryzae-type afIR may lose function in aflatoxin production}

Although aflR could not be amplified from six strains of $A$. oryzae, aflR was still found to exist in three of the A. oryzae strains tested. The sequences of the amplified aflR genes from A. flavus and A. oryzae did not show consistent variations. However, two strains of A. flavus, BCRC 31737 and 30165 , showed consistent variations, together with $A$. flavus var. viridis, A. oryzae var. viridis, A. oryzae and A. oryzae var. effuses, at positions $-90,414,558,800$ and 985 , and can be distinguished from the other strains of A. flavus. These variations cause Cys and Gly to change to Tyr and Ser, respectively, at amino acid residues 267 and 329 (Table 5). We call this type of aflR gene the 'A. oryzae type'. The A. oryzae-type aflR gene has $\mathrm{T}$ instead of $\mathrm{C}$ in the promoter region (position -90). Further studies are required to determine whether this change has an effect on the DNAbinding activity of the AFLR protein or that of other regulators. On the other hand, the amino acid substitutions at positions 267 and 329 of AFLR may significantly change protein activity and eliminate the normal function of the aflR protein. The A. oryzae-type aflR is quite similar to the A. flavus aflR, but can be distinguished from the aflR gene of A. sojae/A. parasiticus (Table 3, Fig. 2). Two A flavus strains (BCRC 30165 and 31737) have the A. oryzae-type aflR gene. Neither strain has a record of aflatoxin production.

The study of Geiser et al. (1998) separated A. flavus isolates into two groups and showed that all $A$. oryzae strains are related to group I. We suspect that all group I isolates carry the A. oryzae-type aflR gene; however, further comparison studies are required. It has been postulated that $A$. oryzae was domesticated from A. flavus (Geiser et al., 1998, 2000; Kurtzman et al., 1986). Further, based on our results, we postulate that when A. flavus strains have the A. oryzae-type aflR, they are non-toxigenic. Kusumoto et al. (1998b) have shown that some strains of $A$. oryzae have an aflR gene but do not produce detectable transcript. Since it is known that the AFLR protein possesses an autoregulation function (Chang et al., 1995b), it is an appealing hypothesis to suggest that the changed amino acid residues of the A. oryzae-type aflR affect the autoregulation function and are responsible for the fact that aflR expression is non-detectable in these strains. We are undertaking further studies to test this hypothesis and/or to discover whether there is another regulatory mechanism responsible for blocking aflR gene expression in A. oryzae.

Additionally, A. flavus BCRC 30010 has A. flavus-type aflR, but does not produce aflatoxin (Wei \& Jong, 1986). A transverson of $\mathrm{C}$ to A occurs in the aflR gene of strain 30010 at position 22, but does not change the expected amino acid residue Arg-8. Since aflatoxin production requires the normal function of the complete aflatoxin biosynthesis gene cluster, we suspect that genes other than aflR are not functioning properly and inhibit aflatoxin production in BCRC 30010.

\section{afIR of A. parasiticus BCRC 33603 is different from that of other strains}

Variations were found in the aflR gene of $A$. parasiticus. In particular, the aflR gene of the type strain $A$. parasiticus BCRC 33603 had different nucleotides from the other $A$. parasiticus strains (BCRC 30150, 30164 and 30110) at positions $-16,59,303,347,349,441,485,704,1030,1037,1206$, 1237, 1422 and 1441 (Table 4). Some of these variations

Table 6. Variation of the aflR gene and AFLR in $A$. parasiticus

Nucleotides subject to variation are shown in underlined type. Amino acids subject to variation are shown in bold type.

\begin{tabular}{|c|c|c|c|}
\hline \multirow[t]{2}{*}{ Sequence } & \multirow[t]{2}{*}{ Position } & \multicolumn{2}{|c|}{ Species } \\
\hline & & $\begin{array}{c}\text { A. parasiticus } \\
\text { 33603* }\end{array}$ & $\begin{array}{c}\text { A. parasiticus } \\
30150,30164,30110\end{array}$ \\
\hline DNA & -16 & $\mathrm{C}$ & $\mathrm{T}$ \\
\hline Amino acid & - & - & - \\
\hline DNA & 59 & CGC & C드 \\
\hline Amino acid & 20 & Arg & Pro \\
\hline DNA & 303 & ACG & ACA \\
\hline Amino acid & 101 & Thr & Thr \\
\hline DNA & 347 & TㄷT & TTT \\
\hline Amino acid & 116 & Ser & Phe \\
\hline DNA & 349 & CAT & TAT \\
\hline Amino acid & 117 & His & Tyr \\
\hline DNA & 441 & ATC & ATA \\
\hline Amino acid & 147 & Iso & Iso \\
\hline DNA & 485 & CTT & CAT \\
\hline Amino acid & 162 & Leu & His \\
\hline DNA & 704 & TGC & TĆC \\
\hline Amino acid & 235 & Cys & Ser \\
\hline DNA & 1030 & GTG & ATG \\
\hline Amino acid & 344 & Val & Met \\
\hline DNA & 1037 & AGT & $\mathrm{AC} \underline{\mathrm{T}}$ \\
\hline Amino acid & 346 & Ser & Thr \\
\hline DNA & 1206 & GAC & GAT \\
\hline Amino acid & 402 & Asp & Asp \\
\hline DNA & 1237 & $\underline{\text { GCG }}$ & ACG \\
\hline Amino acid & 413 & Ala & Thr \\
\hline DNA & 1422 & $\mathrm{G}$ & A \\
\hline Amino acid & - & - & - \\
\hline DNA & 1441 & C & $\mathrm{T}$ \\
\hline Amino acid & - & - & - \\
\hline
\end{tabular}

${ }^{*}$ Type strain. 
changed amino acids: at residues 20, 116, 117, 162, 235, 344, 346 and 413 (Table 6). Some studies have identified a duplication of the aflR gene in A. parasiticus, present as aflR-1 and aflR-2 (Chang \& Yu, 2002; Cary et al., 2002). Compared with the aflR gene sequence at GenBank, the aflR gene of BCRC 33603 amplified in this study is closer to aflR1, and the aflR genes of BCRC 33110, 30164 and 30150 are closer still to aflR-2. Whether aflR-1 or aflR-2 is used, $A$. parasiticus can be differentiated from other species in Aspergillus section Flavi by using the aflR gene (Table 4, Fig. 2).

In conclusion, by using amplification and sequencing of the aflR gene, we have demonstrated that the aflR gene cannot be amplified from some strains of $A$. oryzae and $A$. sojae, and therefore is likely to be missing or highly abnormal. In the strains of $A$. sojae from which the aflR gene can be amplified, the nucleotide sequence is altered such that 62 amino acids are truncated in the AFLR protein. In strains of $A$. oryzae from which the aflR gene can be amplified, the gene shows differences from aflR of toxigenic A. flavus. Further studies are required to prove whether the strains with an $A$. oryzaetype aflR gene have a loss of function in aflatoxin production or whether other regulation mechanisms exist.

\section{ACKNOWLEDGEMENTS}

This work was supported by grants (contract no. 89-EC-2-A-17-0263) from the Ministry of Economic Affairs, Taiwan. We thank Professor George A. Marzluf, Department of Biochemistry, Ohio State University, USA, and Dr Wen-Shen Chu, Food Industry Research and Development Institute, Hsinchu, Taiwan, for reviewing the manuscript and for valuable comments.

\section{REFERENCES}

Bennett, J. W., Chang, P.-K. \& Bhatnagar, D. (1997). One gene to whole pathway: the role of norsolorinic acid in aflatoxin research. Adv Appl Microbiol 45, 1-15.

Cary, J. W., Dyer, J. M., Ehrlich, K. C., Wright, M. S., Liang, S.-H. \& Linz, J. E. (2002). Molecular and functional characterization of a second copy of the aflatoxin regulatory gene, aflR-2, from Aspergillus parasiticus. Biochim Biophys Acta 1576, 316-323.

Chang, P.-K. (2004). Lack of interaction between AFLR and AFLJ contributes to nonaflatoxigenicity of Aspergillus sojae. J Biotechnol 107, 245-253.

Chang, P. K. \& Yu, J. (2002). Characterization of a partial duplication of the aflatoxin gene cluster in Aspergillus parasiticus ATCC 56775. Appl Microbiol Biotechnol 58, 632-636.

Chang, P.-K., Cary, J. W., Bhatnagar, D., Cleveland, T. E., Bevvett, J. E., Line, J. E., Woloshuk, C. P. \& Payne, G. A. (1993). Cloning of the Aspergillus parasiticus apa-2 gene associated with the regulation of aflatoxin biosynthesis. Appl Environ Microbiol 59, 3273-3279.

Chang, P.-K., Bhatnagar, D., Cleveland, T. E. \& Bennett, J. W. (1995a). Sequence variability in homologs of the aflatoxin pathway gene aflR distinguishes species in Aspergillus Section Flavi. Appl Environ Microbiol 61, 40-43.

Chang, P.-K., Ehrlich, K. C., Yu, J., Bhatnagar, D. \& Cleveland, T. E. (1995b). Increased expression of Aspergillus parasiticus aflR, encoding a sequence-specific DNA-binding protein, relieves nitrate inhibition of aflatoxin biosynthesis. Appl Environ Microbiol 61, 2372-2377.

Chang, P.-K., Yu, J., Bhatnagar, D. \& Cleveland, T. E. (1999). The carboxy-terminal portion of the aflatoxin pathway regulatory protein AFLR of Aspergillus parasiticus activates GAL1: : lacZ gene expression in Saccharomyces cerevisiae. Appl Environ Microbiol 65, 2508-2512.

Ehrlich, K. C., Cary, J. W. \& Montalbano, B. G. (1999a). Characterization of the promoter for the gene encoding the aflatoxin biosynthetic pathway regulatory protein AFLR. Biochim Biophys Acta 1444, 412-417.

Ehrlich, K. C., Montalbano, B. G. \& Cary, J. W. (1999b). Binding of the C6-zinc cluster protein, AFLR, to the promoters of aflatoxin pathway biosynthesis genes in Aspergillus parasiticus. Gene 230, 249-257.

Ehrlich, K. C., Montalbano, B. G. \& Cotty, P. J. (2003). Sequence comparison of aflR from different Aspergillus species provides evidence for variability in regulation of aflatoxin production. Fungal Genet Biol 38, 63-74.

Felsenstein, J. (2004). PHYLIP - Phylogenetic Inference Package, version 3.6. Distributed by the author. Seattle, USA: University of Washington.

Geiser, D. M., Pitt, J. I. \& Taylor, J. W. (1998). Cryptic speciation and recombination in the aflatoxin-producing fungus Aspergillus flavus. Proc Natl Acad Sci U S A 95, 388-393.

Geiser, D. M., Dorner, J. W., Horn, B. W. \& Taylor, J. W. (2000). The phylogenetics of mycotoxin and sclerotium production in Aspergillus flavus and Aspergillus oryzae. Fungal Genet Biol 31, 1-11.

Klich, M. A. \& Pitt, J. I. (1988). Differentiation of Aspergillus flavus from A. parasiticus and other closely related species. Trans Br Mycol Soc 91, 99-108.

Klich, M. A., Yu, J., Chang, P.-K., Mullancy, E. J., Bhatnagar, D. \& Cleveland, T. E. (1995). Hybridization of genes involved in aflatoxin biosynthesis to DNA of aflatoxigenic and non-aflatoxigenic aspergilli. Appl Environ Microbiol 44, 439-443.

Klich, M. A., Montalbano, B. \& Ehrlich, K. (1997). Northern analysis of aflatoxin biosynthesis genes in Aspergillus parasiticus and Aspergillus sojae. Appl Microbiol Biotechnol 47, 246-249.

Kumeda, Y. \& Asao, T. (1996). Single-strand conformation polymorphism analysis of PCR-amplified ribosomal DNA internal transcribed spacers to differentiate species of Aspergillus section flavi. Appl Environ Microbiol 62, 2947-2952.

Kurtzman, C. P., Robnett, M. J. \& Wicklow, D. T. (1986). DNA relatedness among wild and domesticated species in the Aspergillus flavus group. Mycologia 78, 955-959.

Kusumoto, K.-I., Yabe, K., Nogata, Y. \& Ohta, H. (1998a). Aspergillus oryzae with and without a homolog of the aflatoxin biosynthetic gene ver-1. Appl Environ Microbiol 50, 98-104.

Kusumoto, K.-I., Yabe, K., Nogata, Y. \& Ohta, H. (1998b). Transcript of a homolog of aflR, a regulatory gene for aflatoxin synthesis in Aspergillus parasiticus, was not detected in Aspergillus oryzae strains. FEMS Microbiol Lett 169, 303-307.

Lee, C. Z., Liou, G. Y. \& Yuan, G. F. (2004). Comparison of Aspergillus flavus and Aspergillus oryzae by Amplification Fragment Length Polymorphism. Bot Bull Acad Sin 45, 61-68.

Lin, C. H., Tang, C. H. \& Yuan, G. F. (1995). Differentiation of Aspergillus flavus and A. oryzae. Research Report 84-982. Hsinchu, Taiwan: Food Industry Research and Development Institute.

Matsushima, K., Chang, P.-K., Yu, J., Abe, K., Bhatnagar, D. \& Cleveland, T. E. (2001a). Pre-termination in aflR of Aspergillus sojae inhibits aflatoxin biosynthesis. Appl Microbiol Biotechnol 55, $585-589$. 
Matsushima, K., Yashiro, K., Hanya, Y., Abe, K., Yabe, K. \& Hamasaki, T. (2001b). Absence of aflatoxin biosynthesis in koji mold (Aspergillus sojae). Appl Microbiol Biotechnol 55, 771-776.

Murakami, H., Hayashi, K. \& Ushijima, S. (1982). Useful key characters separating three Aspergillus taxa: A. sojae, A. parasiticus, and A. toxicarius. J Gen Appl Microbiol 28, 55-60.

Page, R. D. M. (1996). TREEVIEW: an application to display phylogenetic trees on personal computers. Comput Appl Biosci 12, 357-358.

Payne, G. A., Nystrom, G. J., Bhatnagar, D., Cleveland, T. E. \& Woloshuk, C. P. (1993). Cloning of the afl-2 gene involved in aflatoxin biosynthesis from Aspergillus flavus. Appl Environ Microbiol 59, 156-162.

Takahashi, T., Chang, P.-K., Matsushima, K., Yu, J., Abe, K., Bhatnagar, D., Cleveland, T. E. \& Koyama, Y. (2002). Nonfunctionality of Aspergillus sojae aflR in a strain of Aspergillus parasiticus with a disrupted aflR gene. Appl Environ Microbiol 68, 3737-3743.

Thompson, J. D., Gibson, T. J., Plewniak, F., Jeanmougin, F. \& Higgins, D. G. (1997). The CLUSTAL X windows interface: flexible strategies for multiple sequence alignment aided by quality analysis tools. Nucleic Acids Res 25, 4876-4882.

Trail, F., Mahanti, N. \& Linz, J. (1995). Molecular biology of aflatoxin biosynthesis. Microbiology 141, 755-765.

Watson, A. J., Fuller, L. J., Jeenes, D. J. \& Archer, D. B. (1999). Homologs of aflatoxin biosynthesis genes and sequence of aflR in
Aspergillus oryzae and Aspergillus sojae. Appl Environ Microbiol 65, 307-310.

Wei, D. L. \& Jong, S. C. (1986). Production of aflatoxins by strains of the Aspergillus flavus group maintained in ATCC. Mycopathologia 93, 19-24.

White, T. J., Bruns, T. D., Lee, S. B. \& Taylor, J. W. (1990). Amplification and direct sequencing of fungal ribosomal RNA genes for phylogenetics. In PCR Protocols: a Guide to Methods and Applications, pp. 315-322. Edited by M. A. Innis, D. H. Gelfand, J. J. Sninsky \& T. J. White. San Diego: Academic Press.

Woloshuk, C. P. \& Prieto, R. (1998). Genetic organization and function of the aflatoxin B1 biosynthetic genes. FEMS Microbiol Lett 160, 169-176.

Woloshuk, C. P., Foutz, K. R., Brewer, J. F., Bhatnagar, D., Cleveland, T. E. \& Payne, G. A. (1994). Molecular characterization of aflR, a regulatory locus for aflatoxin biosynthesis. Appl Environ Microbiol 60, 2408-2414.

Yu, J., Chang, P.-K., Cary, J. W., Wright, M., Bhatnagar, D., Cleveland, T. E., Payne, G. A. \& Line, J. E. (1995). Comparative mapping of aflatoxin pathway gene clusters in Aspergillus parasiticus and Aspergillus flavus. Appl Environ Microbiol 61, 2365-2371.

Yuan, G. F., Liu, C. S. \& Chen, C. C. (1995). Differentiation of Aspergillus parasiticus from Aspergillus sojae by random amplification of polymorphic DNA. Appl Environ Microbiol 61, 2384-2387. 